\section{КОМПЬЮТЕРНАЯ ИНЖЕНЕРИЯ}

УДК 681.326

АНАЛІЗ КОРЕКТНОСТІ ГРАФІВ
ПЕРЕХОДІВ КЕРУЮЧИХ АВТОМАТІВ
ПРИ ПОБУДОВІ НDL-МОДЕЛЕЙ
ДЛЯ АВТОМАТИЗОВАНОГО СИНТЕЗУ
ШКІЛЬ О.С., КУЛАК Е.М., ФІЛІППЕНКО I.В.,
ШАКУРА О.Г., ФОМЕНКО В.В.

Розглядається аналіз коректності умов переходів у графових моделях керуючих автоматів, представлених у вигляді HDL-моделей, з точки зору подальшого автоматизованого синтезу. Пропонується метод аналізу графа переходів, що дозволяє отримати ненадлишкову та коректну в запам'ятовуючій частині схемну реалізацію при синтезі HDL-моделі кінцевого автомата.

Ключові слова: кінцевий автомат, граф переходів, HDL-модель, автоматизований синтез, ортогональна булева функція.

Key words: finite state machine, state diagram, HDLmodel, automatic synthesis, orthogonal Boolean function.

\section{1. Вступ}

Серед усієї множини керуючих пристроїв можна виділити пристрої логічного управління, у яких управляючі сигнали (control value) представляються в двійковому алфавіті. Оскільки для реалізації керуючої частини в таких пристроях, як правило, використовуються кінцеві автомати, то ці автомати називаються керуючі автомати (КА). При описі алгоритму функціонування цифрових пристроїв логічного керування в САПР цифрових пристроїв одним із стилів написання коду на мовах опису апаратури (HDL-коду) є стиль автоматного програмування. Суть його полягає у відділенні опису логіки поведінки (за яких умов необхідно виконати ті чи інші дії) від опису його семантики (власне сенсу кожного $з$ дій). Автоматні програми строго структуровані і в них виділено три види функцій: функції переходів, функції виходів та функції призначення нового стану. Автоматні програми також строго шаблонизовані 3 використанням операторів багатопозиційного вибору (switch, case) та умовних операторів (if, elsif-else) [1].

При аналізі надійності систем управління широко використовується поняття ортогональності, як системи несумісних подій [2]. Поняття ортогоналізації також використовується для декомпозиції логічних функцій при синтезі цифрових систем [3] та при перевірці графових моделей цифрових автоматів на коректність [4].

3 точки зору реалізації алгоритму логічного управління структурний автомат це модель пристрою реального часу, яка характеризується видачею визначених вихідних сигналів у визначені моменти часу. Структурний автомат функціонує у автоматному часі, який вимірюється в тактах $\{\mathrm{t}, \mathrm{t}+1, \mathrm{t}+2\}$, тобто автомат переходить 3 одного стану в інший за один автоматний такт. За один автоматний такт автомат формує множину вихідних сигналів та обчислює значення наступного стану.

У аналітичному вигляді модель структурного автомату така $\mathrm{Y}(\mathrm{t})=\mathrm{g}(\mathrm{X}(\mathrm{t}), \mathrm{Z}(\mathrm{t}))$, $\mathrm{Z}(\mathrm{t}+1)=\mathrm{f}(\mathrm{X}(\mathrm{t}), \mathrm{Z}(\mathrm{t}))$, де $\mathrm{g}-$ функція виходів структурного автомату, $\mathrm{f}$ - функція переходів структурного автомата. При цьому $\mathrm{Z}(\mathrm{t}+1) \equiv \mathrm{Z}(\mathrm{t})$, але у наступному такті.

Таким чином, апаратна реалізація моделі структурного автомата (модель Хаффмена), складається 3 комбінаційного і послідовністного компонентів. Послідовністний компонент містить елементи пам'яті, такі як синхронні тригери, які запам'ятовують значення внутрішніх змінних (стан) i дозволяють змінювати його синхронно. Комбінаційний компонент складається з логічних елементів, які реалізують дві логічні функції: функцію виходів, яка обчислює значення вихідних сигналів, і функцію переходів, яка обчислює нові значення елементів пам'яті або внутрішніх змінних (тобто значення наступного стану) [5]. На рис.1 наведена графічна інтерпретація апаратної реалізації структурного автомата.

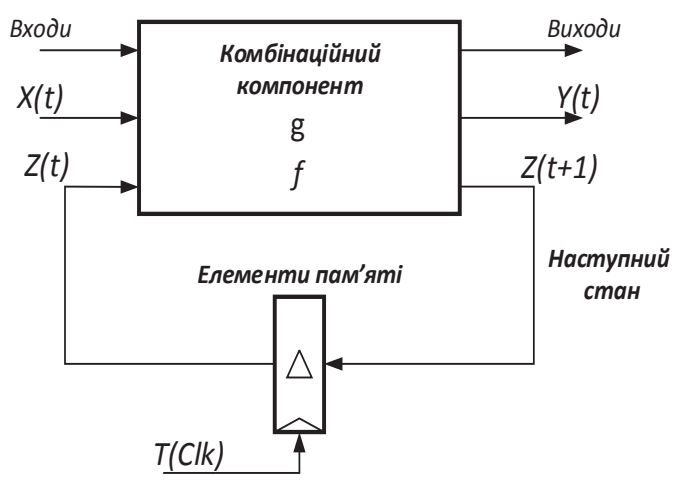

Рис.1. Модель структурного автомата

Як алгоритмічна модель для керуючих автоматів застосовується такий непроцедурний візуальний формалізм, як графи переходів, які в англомовній літературі називаються діаграмами станів (State Diagrams). Зазначимо, що графи переходів $\epsilon$ не тільки візуальним відображенням алгоритму функціонування автомата, але й повною його математичною моделлю [4].

Вершинам графа переходів відповідають стани автомата $\mathrm{a}_{\mathrm{i}}$, дугам відповідають переходи між станами. На дугах автомата моделі Мілі вказуються функції умов переходів 
$\mathrm{f}_{\mathrm{j}}\left(\mathrm{x}_{1}, \mathrm{x}_{2}, \ldots \mathrm{x}_{\mathrm{n}}\right)$ та вихідні (керуючі) сигнали. На дугах автомата моделі Мура вказуються тільки функції умов переходів, а вихідні сигнали вказуються біля вершин.

Предметом розгляду цієї роботи $\epsilon$ аналіз коректної побудови функцій умов переходів графових моделей керуючих автоматів, представлених у вигляді HDL-моделей синтезованої підмножини, 3 точки зору подальшого автоматизованого синтезу.

\section{2. Ортогоналізація логічних функцій умов переходів}

Кожен граф переходів має бути семантично і синтаксично коректний. Перша властивість визначає, чи коректно побудована сама графова модель, а друга - чи немає формальних помилок при іiі побудові. При перевірці синтаксичної коректності граф переходів повинен перевірятися на досяжність, повноту, несуперечність i відсутність генеруючих контурів [4].

При перевірці синтаксичної коректності функцій умов переходів керуючого автомата вони повинні перевірятися на повноту та несуперечність.

На рис. 2 наведений фрагмент графа переходів 3 вершиною $\mathrm{a}_{\mathrm{i}}$, 3 якої виходять $\mathrm{K}$ дуг. Кожній дузі ставиться у відповідність логічний вираз функції умов переходів $\mathrm{f}\left(\mathrm{x}_{1}, \mathrm{x}_{2}, \ldots \mathrm{x}_{\mathrm{n}}\right)$ у диз'юнктивній нормальній формі (ДНФ) :

$$
\begin{aligned}
& \mathrm{f}\left(\mathrm{x}_{1}, \mathrm{x}_{2}, \ldots \mathrm{x}_{\mathrm{n}}\right)=\mathrm{f}_{1}\left(\mathrm{x}_{1}, \mathrm{x}_{2}, \ldots \mathrm{x}_{\mathrm{n}}\right) \vee \ldots \\
& v \mathrm{f}_{\mathrm{j}}\left(\mathrm{x}_{1}, \mathrm{x}_{2}, \ldots \mathrm{x}_{\mathrm{n}}\right) \vee \ldots v \mathrm{f}_{\mathrm{K}}\left(\mathrm{x}_{1}, \mathrm{x}_{2}, \ldots \mathrm{x}_{\mathrm{n}}\right) .
\end{aligned}
$$

Рис. 2. Відображення функцій умов переходів у графовій моделі

Повнота перевіряється для кожної вершини графа переходів шляхом аналізу умов переходів всіх дуг, які виходять 3 цієї вершини, тобто $\mathrm{K}$

$\mathrm{V}_{\mathrm{j}=1} \mathrm{f}_{\mathrm{j}}\left(\mathrm{x}_{1}, \mathrm{x}_{2}, \ldots \mathrm{x}_{\mathrm{n}}\right)=1$. Повнота умов визначається як покриття всіх $2^{\mathrm{n}}$ термів сукупності булевих функцій переходів, де $\mathrm{n}-$ кількість умов переходів (вхідних змінних, які ініціюють переходи 3 цієї вершини), тобто реалізується функція $\mathrm{f}\left(\mathrm{x}_{1}, \mathrm{x}_{2}, \ldots \mathrm{x}_{\mathrm{n}}\right)=1$.

При забезпеченні несуперечливості для кожної вершини графа переходів перевіряється ортогоналізація булевих виразів умов переходів (відсутність спільних термів у булевих виразах умов для різних дуг) функцій переходів для дуг, які виходять з вершини, що розглядається, тобто $\forall\left(\mathrm{f}_{\mathrm{g}} \cdot \mathrm{f}_{\mathrm{h}}=0\right), \mathrm{g} \neq \mathrm{h}[5]$.

Диз'юнктивна нормальна функція алгебри логіки називається ортогональною, якщо всі пї кон'юнктивні терми взаємно-ортогональні. Для такої ДНФ не існує набору значень іiі змінних, що входить більш ніж до однієї елементарної кон'юнкції, тобто на будь-якому наборі значень змінних значення одиниці може прийняти тільки одна кон'юнкція. Якщо логічну функцію представити у вигляді карти Карно, то їх зображення не будуть перетинатися. Прикладом ортогональної ДНФ може служити їі досконала форма (ДДНФ, poc. мовою СДНФ), що складається 3 повних взаємно ортогональних кон'юнкцій [6].

Розглянемо метод побудови ортогональної повної системи функцій переходів для вершини графа переходів.

Введемо такі визначення: $\mathrm{f}$ - повна ДДНФ від $\mathrm{n}$ змінних, тобто $\mathrm{f}\left(\mathrm{x}_{1}, \mathrm{x}_{2}, \ldots \mathrm{x}_{\mathrm{n}}\right)=1-$ булева функція, яка приймає значення 1 на всіх $2^{\text {n }}$ наборах, $\mathrm{f}^{*}$ - повна ДДНФ від (n-1) змінних, $\mathrm{f}^{* *}$ - повна ДДНФ від (n-2) змінних, $\mathrm{f}^{* * *}$ - повна ДДНФ від (n-3) змінних і так далі. Таким чином, $\mathrm{f}=\mathrm{f}^{*}=\mathrm{f}^{* *}=\mathrm{f}^{* * *} \equiv 1$.

Ортогональність термів булевої функції забезпечується за рахунок розкладання за відповідними змінними, з урахуванням повноти розкладання за всіма змінними [7].

За першою теоремою розкладання:

$$
\begin{aligned}
& f=\overline{x_{1}} \cdot f^{*} \vee x_{1} \cdot f^{*}=\overline{x_{1}} \cdot 1 \vee x_{1} \cdot f^{*}=\overline{x_{1}} \vee x_{1} \cdot f^{*}=\overline{x_{1}} \vee \\
& \vee x_{1}\left(\overline{x_{2}} \vee x_{2} \cdot f^{* *}\right)=\overline{x_{1}} \vee x_{1}\left(\overline{x_{2}} \vee x_{2}\left(\overline{x_{3}} \vee x \cdot f^{* * * *}\right)\right)= \\
& =\overline{x_{1}} \vee x_{1}\left(\overline{x_{2}} \vee x_{2}\left(\overline{x_{3}} \vee x_{3} \cdot\left(\ldots \cdot\left(\overline{x_{n}} \vee x_{n}\right)\right)\right)\right) .
\end{aligned}
$$

Таким чином, повна булева функція від $\mathrm{n}$ змінних розкладається мінімум на $(\mathrm{n}+1)$ кон'юнкцій при збереженні суттєвості всіх n змінних.

Як приклад розглянемо повну ДДНФ від трьох змінних $\mathrm{f}\left(\mathrm{x}_{1}, \mathrm{x}_{2}, \mathrm{x}_{3}\right)=1$. За визначенням ДДНФ $\epsilon$ ортогональною. Запишемо повну ДДНФ та виконаємо розкладання по $\mathrm{x}_{1} 3$ заміною лівої частини розкладання у дужках на 1 :

$$
\begin{aligned}
& f\left(x_{1}, x_{2}, x_{3}\right)=\overline{x_{1}} \overline{x_{2}} \overline{x_{3}} \vee \overline{x_{1}} \overline{x_{2}} x_{3} \vee \overline{x_{1}} x_{2} \overline{x_{3}} \vee \\
& \vee \overline{x_{1}} x_{2} x_{3} \vee x_{1} \overline{x_{2}} \overline{x_{3}} \vee x_{1} \overline{x_{2}} x_{3} \vee x_{1} x_{2} \overline{x_{3}} \vee x_{1} x_{2} x_{3}= \\
& =\overline{x_{1}}\left(\overline{x_{2}} \overline{x_{3}} \vee \overline{x_{2}} x_{3} \vee x_{2} \overline{x_{3}} \vee x_{2} x_{3}\right) \vee x_{1}\left(\overline{x_{2}} \overline{x_{3}} \vee\right. \\
& \left.\vee \overline{x_{2}} x_{3} \vee x_{2} \overline{x_{3}} \vee x_{2} x_{3}\right)=\overline{x_{1}} \cdot 1 \vee x_{1} \cdot\left(\overline{x_{2}} \overline{x_{3}} \vee \overline{x_{2}} x_{3} \vee\right. \\
& \left.\vee x_{2} \overline{x_{3}} \vee x_{2} x_{3}\right)=\overline{x_{1}} \vee x_{1}\left(\overline{x_{2}} \overline{x_{3}} \vee \overline{x_{2}} x_{3} \vee x_{2} \overline{x_{3}} \vee x_{2} x_{3}\right) .
\end{aligned}
$$


Виконаємо аналогічно процедуру розкладання по $\mathrm{x}_{2}$ для виразу у дужках. Розкриємо дужки та отримаємо повну ортогональну функцію від трьох змінних:

$$
\begin{aligned}
& f\left(x_{1}, x_{2}, x_{3}\right)=\overline{x_{1}} \vee x_{1}\left(\overline{x_{2}}\left(x_{3} \vee \overline{x_{3}}\right) \vee x_{2}\left(\overline{x_{3}} \vee x_{3}\right)\right)= \\
& =\overline{x_{1}} \vee x_{1}\left(\overline{x_{2}} \cdot 1 \vee x_{2}\left(\overline{x_{3}} \vee x_{3}\right)\right)=\overline{x_{1}} \vee x_{1}\left(\overline{x_{2}} \vee x_{2} \overline{x_{3}} \vee(1)\right. \\
& \left.\vee x_{2} x_{3}\right)=\overline{x_{1}} \vee x_{1} \overline{x_{2}} \vee x_{1} x_{2} \overline{x_{3}} \vee x_{1} x_{2} x_{3} .
\end{aligned}
$$

Виходячи 3 цього, можна зробити висновок, що повна ортогональна функція від $\mathrm{n}$ змінних має в своєму складі не менше, ніж $(\mathrm{n}+1)$ кон'юнкцій. Отже, $з$ кожного стану автомата 3 функцією умов переходів від $\mathrm{n}$ змінних $\mathrm{f}\left(\mathrm{x}_{1}, \mathrm{x}_{2}, \ldots \mathrm{x}_{\mathrm{n}}\right)$ повинно бути не менше, ніж $(\mathrm{n}+1)$ переходів.

Одним iз способів візуального аналізу ортогональності функцій переходів $\epsilon$ представлення ортогональних функцій на картах Карно. На рис. 3, а зображена карта Карно для ортогональної функції (1). 3 наведеної карти видно, що для ортогональної функції обведення груп одиниць для повної ДДНФ не перетинаються, тобто кон'юнкції не мають спільних частин.

На рис. 3,б представлена карта Карно для ортогональної

функції $\mathrm{f}\left(\mathrm{x}_{1}, \mathrm{x}_{2}, \mathrm{x}_{3}\right)=\overline{\mathrm{x}_{1}} \vee \mathrm{x}_{1} \overline{\mathrm{x}_{2}} \vee \mathrm{x}_{1} \mathrm{x}_{2} \overline{\mathrm{x}_{3}} \quad, \quad$ але наведена функція не $\epsilon$ повною, бо в ній відсутнє обведення $\mathrm{x}_{1} \mathrm{x}_{2} \mathrm{x}_{3}$. Це обумовлено тим, що при побудові вказаної функції порушено правило іï повноти, тобто $\mathrm{f}^{*} \neq 1$.

На рис. 3,в також представлена карта Карно для ортогональної функції

$$
\mathrm{f}\left(\mathrm{x}_{1}, \mathrm{x}_{2}, \mathrm{x}_{3}\right)=\overline{\mathrm{x}_{1}} \vee \mathrm{x}_{1} \overline{\mathrm{x}_{2}} \vee \mathrm{x}_{1} \mathrm{x}_{2},
$$

але наведена функція теж не $\epsilon$ повною, бо в ній відсутня змінна $\mathrm{x}_{3}$. Це обумовлено тим, що при побудові вказаної функції порушено правило наявності у повній функції не менше, ніж $(\mathrm{n}+1)$ кон'юнкцій.
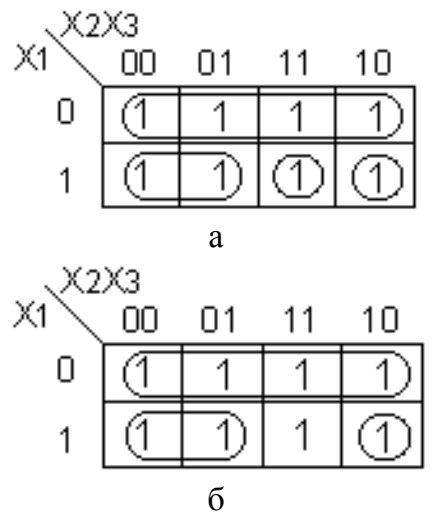

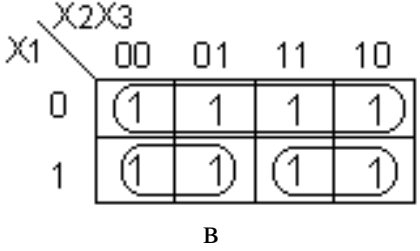

Рис. 3. Карти Карно для ортогональних функцій

Ще одним способом візуального аналізу ортогоналізації повних булевих функцій $\epsilon$ використання бінарних дерев рішень у формі ГСА (рис. 4).

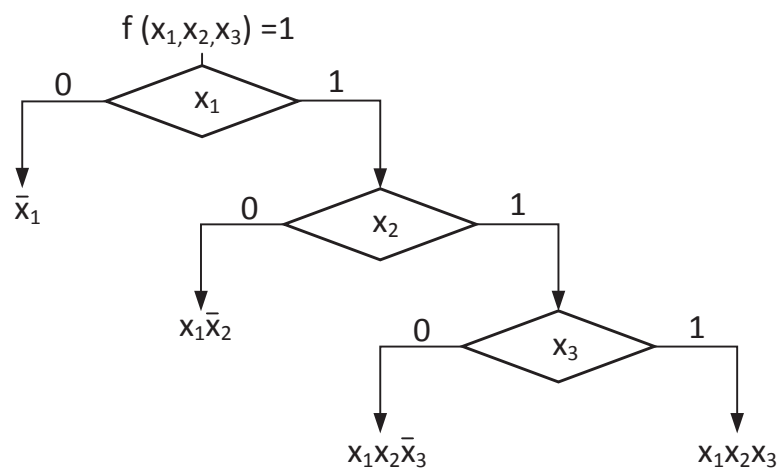

Рис. 4. Дерево ортогональних рішень

Дерево ортогональних рішень на цьому рисунку відповідає карті Карно, зображеній на рис. 3,а. Тут 3 умовних вершини та 4 переходи (шляхи розгалуження), умови переходу по кожній з гілок відповідають термам ортогональної ДНФ (1).

При представленні функції умов переходів бінарним деревом ортогональних рішень можна точно визначити необхідне число переходів. При незалежності умов $\mathrm{x}_{1}, \mathrm{x}_{2}, \ldots \mathrm{x}_{\mathrm{n}}$ одної від одної це число буде дорівнювати $(\mathrm{m}+1)$, де $\mathrm{m}-$ число вершин дерева (але не змінних, оскільки змінні у вершинах таких дерев можуть повторюватися).

3. Аналіз коректності HDL-моделей керуючих автоматів при автоматизованому синтезі

У цьому розділі наведена ілюстрація запропонованих теоретичних викладень на прикладах графових моделей автоматів, їх опису на мові VHDL, результатів їх моделювання та синтезу.

Розглянемо приклад графа переходів (рис. 5) 3 коректними умовами переходів із стану $\mathrm{a}_{1}$ відповідно до дерева ортогональних рішень, наведеного на рис. 4. Функція умов переходів із стану $\mathrm{a}_{1}$ ортогональна, отже, умови переходів несуперечливі. Крім того, функція $є$ повною. VHDL-модель цього автомата наведена на рис. 6. 


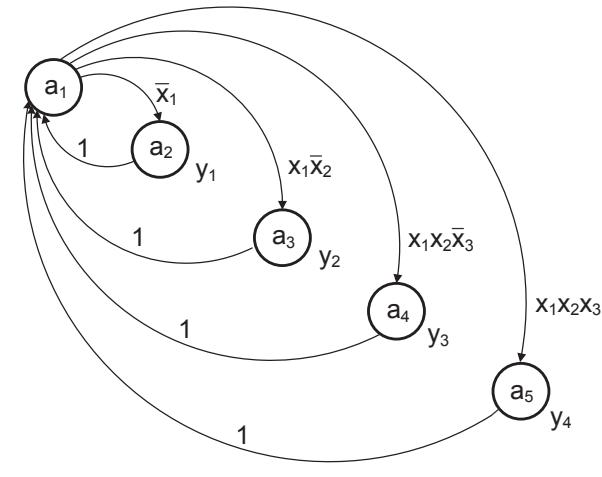

Рис. 5. Граф переходів автомата Мура з коректними умовами переходів

library IEEE;

use IEEE.std_logic_1164.all;

entity Fsm right is

port $(x \overline{1}, x 2, x 3$, Clk, reset: in STD_LOGIC;

y1, y2, y3, y4: out STD_LOGIC);

end;

architecture Fsm_right of Fsm_right is

type State_type is (a1, a2, a3, a4, a5); begin

signal State, NextState: State type;

Sreg0_CurrentState: process (Clk, reset)

begin

if reset=' 1 ' then State $<=a 1$;

elsif Clk'event and Clk = ' 1 '

then State $<=$ NextState;

end if;

end process;

Sreg0_NextState: process (State, x1, x2, x3)

begin

case State is

when $a 1=>$ if $x 1={ }^{\prime} 0$ ' then NextState $<=a 2$;

elsif $\times 2=' 0$ ' then NextState $<=a 3$;

elsif $\times 3={ }^{\prime} 0$ ' then NextState $<=a 4$;

else NextState <= a5;

end if;

when a2 $=>$ NextState $<=a 1$;

when a3 $=>$ NextState $<=a 1$;

when $a 4=>$ NextState $<=a 1$;

when a5 $=>$ NextState $<=a 1$;

when others $=>$ NextState $<=a 1$;

end case;

end process;

y1 <= ' 1 ' when State=a2 else ' 0 ';

y2 <= ' 1 ' when State=a3 else ' 0 ';

y3 $<=$ ' 1 ' when State=a4 else ' 0 ',

y4 <= ' 1 ' when State=a5 else ' 0 ',

end;

Рис. 6. VHDL-модель автомата Мура 3 коректними умовами переходів

Часові діаграми роботи автомата наведені на рис. 7. На ньому відображені результати моделювання в системі Active-HDL ALDEC на усіх комбінаціях наборів умов $\mathrm{x}_{1}, \mathrm{x}_{2}, \mathrm{x}_{3}$. Діаграма свідчить, що функція умов переходів $\epsilon$ повною та ортогональною і повністю повторює приклад 3 рис. 4. У період 3150 до 950 нс автомат переходить у стан $\mathrm{a}_{2} \quad\left(\mathrm{y}_{1}=1\right)$, доки виповнюється умова $\overline{\mathrm{x}}_{1}$, тобто $\left(\mathrm{x}_{1}=0\right)$, та повертається зворотно в $\mathrm{a}_{1}\left(\mathrm{y}_{1}=0\right)$. В період 3 950 до 1350 нс автомат переходить в стан $\mathrm{a}_{3}$ $\left(\mathrm{y}_{2}=1\right)$, доки виконується умова $\mathrm{x}_{1} \overline{\mathrm{x}}_{2}$, тобто $\left(\mathrm{x}_{1}=1, \mathrm{x}_{2}=0\right)$, та повертається зворотно в $\mathrm{a}_{1}$ $\left(\mathrm{y}_{2}=0\right)$. У період з 1350 до $1550 \mathrm{нс}$ автомат переходить в стан $\mathrm{a}_{4}\left(\mathrm{y}_{3}=1\right)$, доки виконується умова $\mathrm{x}_{1} \mathrm{x}_{2} \overline{\mathrm{x}}_{3}$, тобто $\left(\mathrm{x}_{1}=1, \mathrm{x}_{2}=1, \mathrm{x}_{3}=0\right)$, та повертається зворотно в $\mathrm{a}_{1}\left(\mathrm{y}_{3}=0\right)$. У період 3 1550 до 1750 нс автомат переходить в стан $\mathrm{a}_{5}$ $\left(\mathrm{y}_{4}=1\right)$, доки виконується умова $\mathrm{x}_{1} \mathrm{x}_{2} \mathrm{x}_{3}$, тобто $\left(\mathrm{x}_{1}=1, \mathrm{x}_{2}=1, \mathrm{x}_{3}=1\right)$, та повертається назад в $\mathrm{a}_{1}$ $\left(\mathrm{y}_{4}=0\right)$.

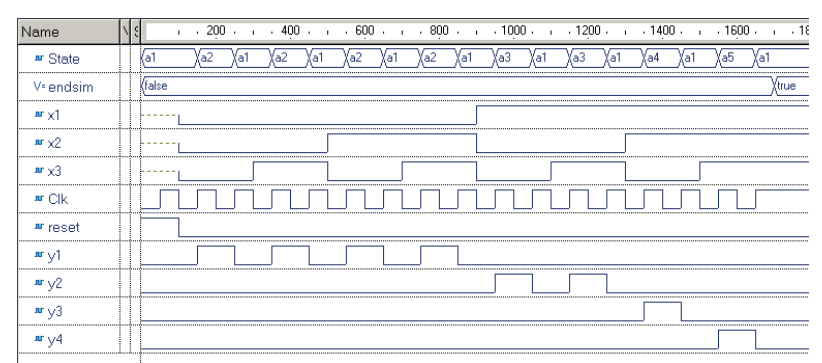

Рис. 7. Часові діаграми автомата Мура з коректними умовами переходів

Розглянемо наступний приклад графа переходів (рис. 8). У ньому умови переходів із стану $\mathrm{a}_{1}$ некоректні з точки зору ортогоналізації функції умов переходів, при переході в $\mathrm{a}_{4} \mathrm{i} \mathrm{a}_{5}$ в записі термів бракує змінної $\mathrm{x}_{1}$, але вони не суперечать умовам переходів $\mathrm{x}_{1} \mathrm{x}_{2} \overline{\mathrm{x}}_{3}$ та $\mathrm{x}_{1} \mathrm{x}_{2} \mathrm{x}_{3}$. Функції умов переходів $є$ повними.

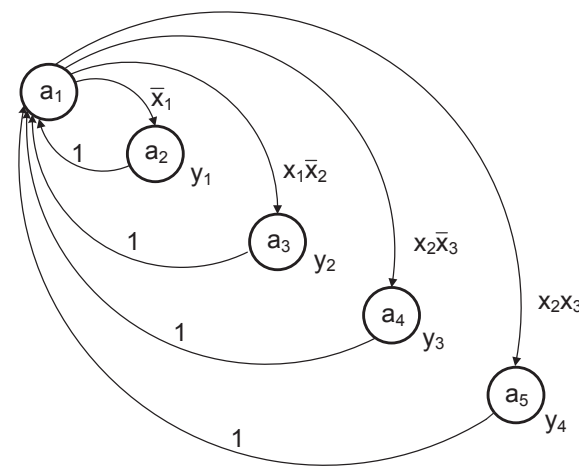

Рис. 8. Граф переходів автомата Мура 3 несуперечливими неповними умовами переходів

Переходи із стану $\mathrm{a}_{1}$ можуть бути записані на мові VHDL так (рис.9, а або б). При цьому такий опис стилістично не $є$ коректним, але не $\epsilon$ суперечливим та при моделюванні дає такі ж результати, що і на рис. 7. 
when $a 1=>$ if $x 1=$ ' 0 ' then NextState $<=a 2$; elsif $\times 1=$ ' 1 'and $\times 2=$ '0' then NextState $<=$ a3; elsif $\times 2=' 1$ 'and $\times 3=$ ' 0 ' then NextState $<=$ a4; else NextState $<=$ a5; end if;

when $a 1=>$ if $x 1={ }^{\prime} 0$ ' then NextState $<=a 2$; elsif $\times 1=$ ' 1 'and $\times 2=$ '0' then NextState $<=$ a3 elsif $\times 2=$ ' 1 'and $\times 3=$ '0' then NextState $<=a 4$; elsif $\times 2=' 1$ 'and $x 3=$ ' 1 ' then NextState $<=$ a5; end if;

\section{6}

Рис. 9. Фрагменти VHDL- моделі автомата Мура 3 несуперечливими неповними умовами переходів

Крім того, моделі автоматів, що наведені на рис.6 та 9, при синтезі дають абсолютно однакові коректні результати. Синтез виконувався в системі XILINX ISE.

Далі розглянемо приклад графа переходів (рис. 10) 3 відсутнім переходом (по умові $\mathrm{x}_{1} \mathrm{x}_{2} \mathrm{x}_{3}$ ) та неповною умовою переходу із стану $\mathrm{a}_{1}$ в стан $\mathrm{a}_{4}$ : $\mathrm{x}_{2} \overline{\mathrm{x}}_{3}$ замість $\mathrm{x}_{1} \mathrm{x}_{2} \overline{\mathrm{x}}_{3}$. Функція умов переходів $\mathrm{y}$ даному випадку $є$ неортогональною та неповною. Фрагмент VHDL- моделі цього автомата наведений на рис. 11.

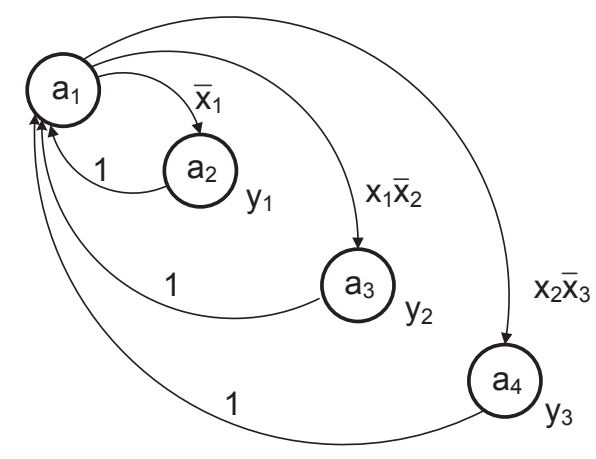

Рис. 10. Граф переходів автомата Мура з відсутнім переходом

when $a 1=>$ if $x 1={ }^{\prime} 0$ ' then NextState $<=a 2$

elsif $\times 1=' 1$ 'and $\times 2={ }^{\prime} 0$ ' then NextState $<=$ a3;

elsif $x 2=' 1$ 'and $x 3={ }^{\prime} 0$ ' then NextState $<=a 4$;

end if;

Рис. 11. Фрагмент VHDL-моделі автомата Мура 3 відсутнім переходом

При моделюванні роботи даного автомата (рис. 12) на перший погляд все добре, але насправді змінна $\mathrm{x}_{3}$ тут виявляється несуттєвою, як на рис. 3 , в. На наборі $\mathrm{x}_{1}, \mathrm{x}_{2}, \mathrm{x}_{3}=111$ автомат не має переходити в жодний стан, але система моделювання переводить його в стан $\mathrm{a}_{4}$. Так само при наборі умов $\mathrm{x}_{1}, \mathrm{x}_{2}, \mathrm{x}_{3}=010$, автомат може перейти в два стани $\mathrm{a}_{2} \mathrm{i} \mathrm{a}_{4}$, чого не повинно бути при правильній роботі автомата, але система моделювання маскує таку ситуацію, переводячи автомат в стан $\mathrm{a}_{2}$. У цьому прикладі $\epsilon$ i відсутність повноти, i наявність суперечності умов переходів, але на етапах аналізу синтаксису і моделювання це явно не проявляється.

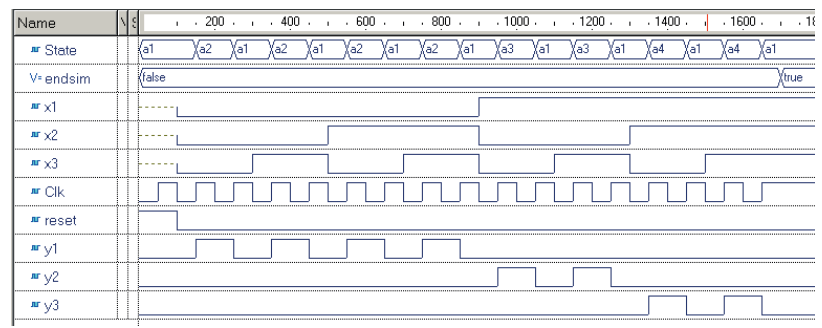

Рис. 12. Часові діаграми автомата Мура з відсутнім переходом

При синтезі цього автомата виникають проблеми. Критичної помилки не виникає, але з'являється попередження про появу чотирьох тригерів типу latch на додаток до чотирьох тригерів типу flip-flop: WARNING: Xst:737 Found 4-bit latch for signal $<$ NextState $>$. Latches may be generated from incomplete case or if statements. We do not recommend the use of latches in FPGA/CPLD designs, as they may lead to timing problems. Отже, замість двох тригерів для чотирьох станів синтезується 8 тригерів двох типів. Цього не повинно бути в коректно синтезованому автоматі.

На завершення розглянемо приклад графа переходів (рис. 13) 3 суперечливою умовою переходу із стану $\mathrm{a}_{1}$ в стан $\mathrm{a}_{4}: \overline{\mathrm{x}}_{2} \mathrm{x}_{3}$ замість $\mathrm{x}_{1} \mathrm{x}_{2} \overline{\mathrm{x}}_{3}$. Фрагмент VHDL-моделі цього автомата наведений на рис. 14.

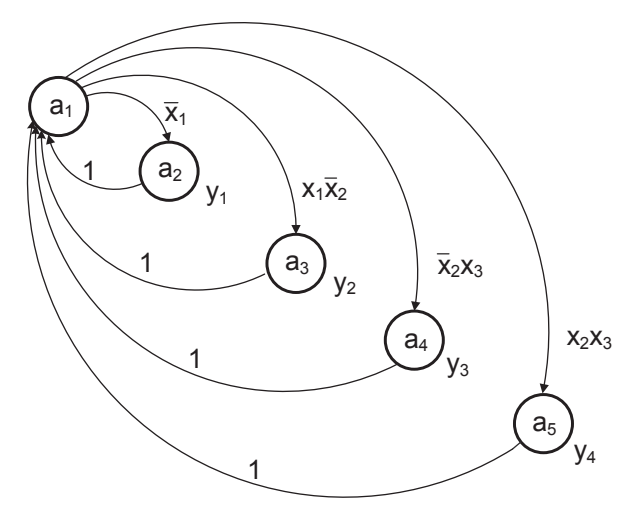

Рис. 13. Граф переходів автомата Мура 3 суперечливою умовою переходу

when $a 1=>$ if $x 1={ }^{\prime} 0$ ' then NextState $<=a 2$; elsif $x 1=' 1$ ' and $x 2=' 0$ ' then NextState $<=a 3$; elsif $x 2={ }^{\prime} 0$ ' and $x 3=' 1$ ' then NextState $<=a 4$; elsif $x 2=' 1$ 'and $x 3=' 1$ ' then NextState $<=a 5$; end if;

Рис. 14. Фрагмент VHDL-моделі автомата Мура 3 суперечливою умовою переходу 
При моделюванні роботи цього автомата (рис. 15) явно спостерігається тільки неможливість переходу в стан а 4 ні при яких наборах умов $\mathrm{x}_{1}, \mathrm{x}_{2}, \mathrm{x}_{3}$. Як і в попередньому прикладі, система моделювання маскує помилкову ситуацію, при якій створюються умови переходу автомата в декілька станів. Наприклад, при наборі умов $\mathrm{x}_{1}, \mathrm{x}_{2}, \mathrm{x}_{3}=001$ автомат повинен перейти в два стани $\mathrm{a}_{2} \mathrm{i} \mathrm{a}_{4}$, при наборі умов $\mathrm{x}_{1}, \mathrm{x}_{2}, \mathrm{x}_{3}=101$ автомат повинен перейти в $\mathrm{a}_{3} \mathrm{i} \mathrm{a}_{4}$. Також маскує помилкову ситуацію, при якій створюються умови, коли автомат не повинен переходити в жоден стан, наприклад, при наборі умов $\mathrm{x}_{1}, \mathrm{x}_{2}, \mathrm{x}_{3}$ $=110$. У даному прикладі також $є$ відсутність повноти та наявність суперечності умов переходів, але на етапах аналізу синтаксису це ніяк не проявляється, а на етапі моделювання явно видно тільки те, що автомат ніколи не переходить в стан $\mathrm{a}_{4}$.

При синтезі теж виникають проблеми. З'являється попередження про появу п'яти тригерів типу latch на додаток до п'яти тригерів типу flip-flop:Xst:737 - Found 5-bit latch for signal $<$ NextState $>$. Latches may be generated from incomplete case or if statements.

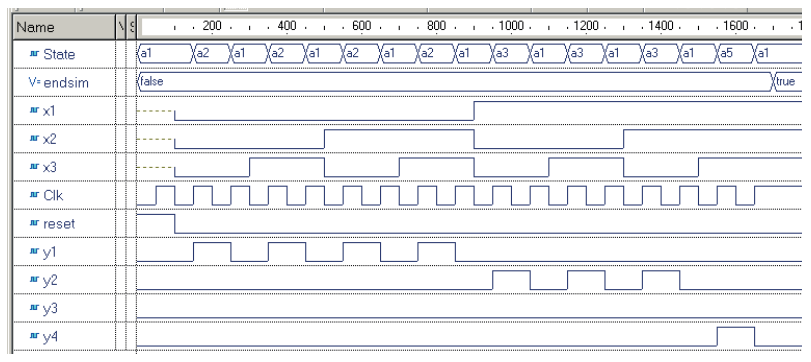

Рис. 15. Часові діаграми автомата Мура 3 суперечливою умовою переходу

Таким чином, показано, що проблеми, пов'язані 3 некоректними умовами, можуть проявитися тільки в процесі синтезу, тому перевірку умов переходів на несуперечність і повноту необхідно виконувати ще на етапі формування моделі графа переходів автомата.

\section{4. Висновки}

В результаті проведених досліджень було показано:

1) Функція умов переходів $\mathrm{f}\left(\mathrm{x}_{1}, \mathrm{x}_{2}, \ldots \mathrm{x}_{\mathrm{n}}\right)$ несуперечлива, якщо вона ортогональна.

2) Ортогональна функція умов переходів $\mathrm{f}\left(\mathrm{x}_{1}, \mathrm{x}_{2}, \ldots \mathrm{x}_{\mathrm{n}}\right) \quad \epsilon$ повною, якщо пi покривають усі набори $\mathrm{x}_{1}, \mathrm{x}_{2}, \ldots \mathrm{x}_{\mathrm{n}}$.

3) Число переходів із стану $a_{i} 3$ функцією умов переходів $\mathrm{f}\left(\mathrm{x}_{1}, \mathrm{x}_{2}, \ldots \mathrm{x}_{\mathrm{n}}\right)$ має бути не менше $(\mathrm{n}+1)$, де $\mathrm{n}$ - число змінних.
4) Число переходів із стану $\mathrm{a}_{\mathrm{i}} 3$ функцією умов переходів має бути рівне $(\mathrm{m}+1)$, де $\mathrm{m}-$ число вершин дерева ортогональних рішень.

5) При невиконанні п. 1-4 висновків синтезується автомат 3 надмірним числом тригерів типу flip-flop та неприпустимою появою такого ж числа тригерів типу latch.

Наукова новизна полягає в тому, що запропоновано метод аналізу графа переходів кінцевого автомата на коректність умов переходів, що дозволяє отримати ненадмірну, коректну з точки зору запам'ятовуючої частини, схемну реалізацію при синтезі HDL-моделі кінцевого автомата.

Практична значущість: в силу особливостей роботи системи моделювання, відсутні переходи або суперечливі умови переходів на етапі перевірки синтаксису не фіксуються, на етапі моделювання вони можуть залишитися непоміченими і тільки після автоматизованого синтезу виявляються проблеми. Тому перевірка коректності умов переходів повинна перевірятися на етапі побудови моделі графа автомата. Це $є$ актуальним в системах логічного управління, в порівнянні 3 пристроями мікропрограмного управління, де умови на графі переходів записуються по бінарному дереву умов у граф-схемі алгоритму (ГСА), що описує операційний автомат. У зв'язку 3 цим, ймовірність помилки значно менша в порівнянні 3 автоматами логічного управління, де ГСА не використовуються, як правило, а закон управління описується графом переходів.

Для аналізу функції умов переходів до 5 змінних можна використати карти Карно, але для більшого числа змінних і у разі автоматизації аналізу зручніше використати кубічне числення 3 представленням функцій умов переходів у вигляді багатовимірних векторів (кубів) [8].

Литература: 1. Шкіль А.С. Автоматизированное проектирование систем логического управления с использованием шаблонов автоматного программирования / А.С. Шкиль, Э.Н. Кулак, И.В. Филиппенко, Д.Е. Кучеренко, М.В. Гога. // Радіоелектроніка та інформатика. 2018. №3. С. 75-81. 2. Рябинин И.А. Надежность и безопасность структурно-сложных систем / И.А. Рябинин. СПб.: Изд-во С.-Петерб. ун-та, 2007. 276с. 3. Бибило П.Н. Синтез логических схем с использованием языка VHDL / П.Н. Бибило. М.: СОЛОН-Р, 2009. 384 с.: 4. Шальто A.A. SWITCH-технология. Алгоритмизация и программирование задач логического управления / А.А. Шалыто. СПб.: Наука, 1998. 628 с. 5. Баранов С.И. Синтез микропрограммных автоматов (граф схемы и автоматы) / С.И.Баранов. Л.:Энергия, 1979. 232 с. 6. Закревский А.Д. Логические основы проектирования дискретных устройств / А.Д. Закревский, Ю.В. Поттосин, Л.Д. Черемисинова. М.: ФИЗМАТЛИТ, 2007. 592 с. 7. Шалыто А.А. Новый 
метод вычисления булевых формул / А.С.Ковалев, А.П.Лукьянова, А.А.Шалыто. [Электронный ресурс] Движение за открытую проектную документацию Режим доступа: www / URL: http://is.ifmo.ru/download/lbgmx.pdf. - Загл. с экрана. 8. Хаханов В.И. Техническая дивгностика элементов и узлов персональных компьютеров / В.И. Хаханов - К.: I3MH, 1997. $308 \mathrm{c}$.

\section{Transliterates bibliography:}

1. Shkil A.S. Avtomatizirovannoe proektirovanie sistem logicheskogo upravlenija $\mathrm{s}$ ispol'zovaniem shablonov avtomatnogo programmirovanija / A.S. Shkil', Je.N. Kulak, I.V. Filippenko, D.E. Kucherenko, M.V. Goga. // Radioelektronika ta informatika. 2018. №3. S. 75-81.

2. Rjabinin I.A. Nadezhnost' i bezopasnost' strukturnoslozhnyh sistem / I.A. Rjabinin. SPb.: Izd-vo S.-Peterb. un-ta, 2007. 276s.

3. Bibilo P.N. Sintez logicheskih shem s ispol'zovaniem jazyka VHDL / P.N. Bibilo. M.: SOLON-R, 2009. 384 s.: 4. Shalyto A.A. SWITCH-tehnologija. Algoritmizacija i programmirovanie zadach logicheskogo upravlenija / A.A. Shalyto. SPb.: Nauka, 1998. 628 s.

5. Baranov S.I. Sintez mikroprogrammnyh avtomatov (graf shemy i avtomaty) / S.I.Baranov. L.:Jenergija, 1979. $232 \mathrm{~s}$.

6. Zakrevskij A.D. Logicheskie osnovy proektirovanija diskretnyh ustrojstv / A.D. Zakrevskij, Ju.V. Pottosin, L.D. Cheremisinova. - M.: FIZMATLIT, 2007. 592 s.

7. Shalyto A.A. Novyj metod vychislenija bulevyh formul / A.S.Kovalev, A.P.Luk'janova, A.A.Shalyto. [Jelektronnyj resurs] Dvizhenie za otkrytuju proektnuju dokumentaciju - Rezhim dostupa: www / URL: http://is.ifmo.ru/download/lbgmx.pdf.

8. Hahanov V.I. Tehnicheskaja divgnostika jelementov i uzlov personal'nyh komp'juterov / V.I. Hahanov. K.: IZMN, 1997. $308 \mathrm{~s}$.

Поступила в редколегію 11.03.2019

Рещензент: д-р техн. наук, проф. Кривуля Г.Ф.

Шкіль Олександр Сергійович, канд. техн. наук, доцент кафедри АПОТ ХНУРЕ. Наукові інтереси: діагностика цифрових систем, дистанційна освіта. Адреса: Україна, 61166, Харків, пр. Науки, 14, тел. 702-13-26.
Кулак Ельвіра Миколаївна, канд. техн. наук, доцент кафедри АПОТ ХНУРЕ. Наукові інтереси: автоматизоване проектування цифрових автоматів, тестопридатне проектування. Адреса: Україна, 61166, Харків, пр. Науки, 14, тел. 702-13-26.

Філіппенко Інна Вікторівна, канд. техн. наук, доцент кафедри АПОТ ХНУРЕ. Наукові інтереси: проектування цифрових пристроїв на базі мікроконтролерів, цифрові фільтри. Адреса: Україна, 61166, Харків, пр. Науки, 14, тел. 702-13-26.

Шакура Олексій Геннадійович, студент ХНУРЕ. Наукові інтереси: автоматизоване проектування цифрових автоматів. Адрес: Україна, 61166, Харків, пр. Науки, 14, тел. 702-13-26.

Фоменко Владислав Володимирович, студент ХНУРЕ. Наукові інтереси: верифікація моделей цифрових автоматів Адреса: Україна, 61166, Харків, пр. Науки, 14, тел. 702-13-26.

Shkil Alexander Sergeevich, PhD, Associate Professor, Design Automation Department, KNURE. Scientific interests: diagnostics of digital systems, distance education. Address: Ukraine, 61166, Kharkiv, Nauka Avenue, 14, tel. 702-13-26.

Kulak Elvira Nikolaevna, $\mathrm{PhD}$, Associate Professor, Design Automation Department, KNURE. Scientific interests: automated design of digital machines, HDL. Address: Ukraine, 61166, Kharkiv, Nauka Avenue, 14, tel. 702-13-26.

Filippenko Inna Victorovna, $\mathrm{PhD}$, Associate Professor, Design Automation Department, KNURE. Scientific interests: design based on microcontrollers, digital filters. Address: Ukraine, 61166, Kharkiv, Nauka Avenue, 14, tel. 702-13-26.

Shakura Alexey Gennadievich, student, KNURE. Scientific interests: automated design of digital machines. Address: Ukraine, 61166, Kharkiv, Nauka Avenue, 14, tel. 702-13-26.

Fomenko Vladislav Vladimirovich, student, KNURE. Scientific interests: verification of FSM models. Address: Ukraine, 61166, Kharkiv, Nauka Avenue, 14, tel. 702-1326 . 